\title{
Interação homem-máquina e as formas de comunicação humana
}

\author{
Human-machine interaction and forms of human communication \\ Interacción humano-máquina y formas de comunicación humana
}

Recebido: 18/09/2021 | Revisado: 15/10/2021 | Aceito: 24/10/2021 | Publicado: 26/10/2021

\author{
Lucas Rocha Fernandes \\ ORCID: https://orcid.org/0000-0002-8316-8882 \\ Universidade Federal de Itajubá, Brasil \\ E-mail: d2021010245@unifei.edu.br \\ Sávio Santos Fontana \\ ORCID: https://orcid.org/0000-0003-1128-5446 \\ Universidade Federal de Itajubá, Brasil \\ E-mail: d2021024410@unifei.edu.br \\ Arthur da Mata Figueiredo \\ ORCID: https://orcid.org/0000-0002-2152-0801 \\ Universidade Federal de Itajubá, Brasil \\ E-mail: arthurspfcdmf@unifei.edu.br \\ Pedro de Souza Mattioli \\ ORCID: https://orcid.org/0000-0002-3226-4989 \\ Universidade Federal de Itajubá, Brasil \\ E-mail: pedraomattioli01@unifei.edu.br \\ Priscilla Chantal Duarte Silva \\ ORCID: https://orcid.org/0000-0001-5148-2423 \\ Universidade Federal de Itajubá, Brasil \\ E-mail: priscillachantal@unifei.edu.br
}

\section{Resumo}

A comunicação é o principal meio de propagação da cultura e ferramenta para a integração da sociedade humana. Nos últimos tempos, o avanço da tecnologia da informação vem potencializando esse meio. O objetivodo presente artigo é analisar a forma e o meio como as pessoas usam as máquinas digitais para se comunicarem e interagirem. A Interação Homem-Máquina (IHM) é conceituada e tratada como tema central deste estudo. As principais informações são tiradas de artigos científicos, pesquisas, livros e reportagens. Utiliza-se uma estrutura que caracteriza as problemáticas envolvendo a ética, evolução, dependência e demais impactos da IHM, propondo uma pesquisa tipo survey, em forma de questionário, com perguntas relacionadas ao tema. Os resultados apontam que a maioria da população jovem se interessa pelas máquinas digitais e possui relações com elas, gerando uma dependência por parte dessa população com relação a essas máquinas. Portanto, conclui-se, de maneira geral, que a aceitação e valorização da Interação HomemMáquina no mundo está se intensificando.

Palavras-chave: Comunicação; Tecnologia da informação; Interação homem-máquina; Ética; Evolução; Máquinas digitais.

\begin{abstract}
Communication is the main means of propagating culture and a tool for the integration of human society. In recent times, the advancement of information technology has been enhancing this medium. The purpose of this article is to analyze a way and means that people use as machines to communicate and interact. The Human-Machine Interaction (HMI) is conceived and treated in the article as the central theme of this study. The main information is taken from scientific articles, researches, books and reports. It uses a structure that denounces as problems involving ethics, evolution, dependence and other impacts of the HMI, proposing a type survey, in the form of a questionnaire, with questions related to the topic. The results indicate that the population of the young population is interested in and has relationships with digital machines, generating a dependency on the part of this population in relation to these machines. Therefore, it is generally concluded that the acceptance and appreciation of the Human-Machine Interaction in the world is intensifying.
\end{abstract}

Keywords: Communication; Information technology; Man-machine interaction; Ethics; Evolution; Digital machines.

\section{Resumen}

La comunicación es el principal medio de propagación de la cultura y una herramienta para la integración de la sociedad humana. En los últimos tiempos, el avance de la tecnología de la información ha mejorado este medio. El propósito de este artículo es analizar la forma en que las personas utilizan las máquinas digitales para comunicarse e interactuar. La Interacción Hombre-Máquina (HMI) se conceptualiza y trata en el artículo como el tema central de 
este estudio. La información principal proviene de artículos científicos, investigaciones, libros e informes. Utiliza una estructura que caracteriza los problemas de ética, evolución, dependencia y otros impactos del HMI, proponiendo una investigación tipo encuesta, en forma de cuestionario, con preguntas relacionadas con el tema. Los resultados muestran que la mayoría de la población joven está interesada y tiene relaciones con las máquinas digitales, generando una dependencia por parte de esta población en relación a estas máquinas. Por lo tanto, generalmente se concluye que la aceptación y la apreciación de la Interacción Hombre-Máquina en el mundo se está intensificando.

Palabras clave: Comunicación; Tecnología de la información; Interacción hombre-máquina; Principio moral; Evolución; Máquinas digitales.

\section{Introdução}

Nos anos mais recentes do século XXI, por conta da crescente emergência das tecnologias inovadoras no âmbito da computação, o uso da tecnologia digital se faz cada vez mais presente no cotidiano das pessoas, o que tem levado ao maior contato da humanidade com esse meio de comunicação e interação. O desejo do ser humano de se comunicar por meio dessas tecnologias se evidencia em um estudo da ONU (2019), que alega que cerca de 4 bilhões de pessoas utilizavam a rede mundial de computadores: a internet. Por causa disso, os impactos no próprio comportamento da sociedade podem ser claros.

Segundo Magalhães (2010 apud Suzanna, 2018), a evolução dos periféricos e sistemas de informações provocaram uma mudança do homem com relação à forma de se comunicar. Em análise, ao observar o cotidiano de um indivíduo dos tempos atuais, nota-se o contato frequente com dispositivos móveis e microcomputadores capazes de possuir diversas funcionalidades para estabelecer comunicação. Logo, nota-se um tipo de relação de um organismo biológico e orgânico com um organismo eletrônico e binário, estudada e pensada como uma Interação Homem-Máquina (IHM). Desse modo, por ser tão presente e impactante, torna-se relevante a discussão sobre o tema. "A IHM é um campo de estudo interdisciplinar que procura entender a forma e o meio em que as pessoas utilizam a tecnologia da informação" (Rosa \& Moraes, 2010).

Em ênfase, a motivação do presente artigo parte da necessidade de se discutir a IHM nas formas de comunicação humana, por se tratar de algo que muda o rumo e o comportamento da sociedade contemporânea. A Interação HomemMáquina ganha novas aplicações e, no presente estudo, a interação será abordada em momentos de reconhecimento facial, inteligência artificial, interfaces e designs, ou seja, na maioria dos casos em que há algum tipo de comunicação, a qual a máquina é capaz de contribuir com o ser humano, e vice-versa, colocando em evidência a percepção de uma dimensão digital inclusiva, de suporte e manutenção das demandas de seus criadores.

Portanto, o objetivo deste estudo é discutir a interatividade no mundo tecnológico, construindo uma reflexão sobre seus impactos na vida de um indivíduo, problemas éticos e desafios que enfrenta e soluciona. Nessa perspectiva, procura-se entender e explicar de forma teórica e empírica o assunto tratado, tomando como referência artigos de autoridade e de relevância, ecoando uma estrutura dissertativa argumentativa bem formulada.

\section{Metodologia}

O procedimento metodológico deste estudo parte de uma pesquisa descritiva, de cunho quantitativo sob o métdodo tipo survey com a técnica de questionário realizado virtualmente, utilizando a plataforma de pesquisas do Google, o Google Forms, de modo a analisar o valor da tecnologia para comunicação por meio do histórico de evolução humana, desde o primeiro uso da linguagem ao uso tecnológico para a otimização da interação global. A pesquisa survey é empregada normalmente quando se deseja investigar um problema de pesquisa que demanda informações, por meio de respostas diretas de pesssoas, a fim de que se possa compreender padrões de comportamento e pensamento de uma amostra da população estudada, podendo ter caráter qualitativo, quantitativo ou misto. A pesquisa quantitativa centra-se em resultados quantificáveis para conclusões seguras e confiáveis (Gil, 1999; Cervo \& Bervian, 2002). 
Neste estudo que mostra como a evolução comunicativa teve avanços a partir do uso tecnológico e explica os benefícios deles, mostrando de forma detalhada o caminho de evolução da interação homem-máquina a partir dos primeiros meios tecnológicos, optou-se por uma análise quantitativa, porém não proba. Normalmente, o survey é usado para se estudar um segmento ou parcela de uma população.

\section{Formas de Comunicação e Interação Humana}

Desde os primórdios, o homem tem objetivos em comum, como a caça, sobrevivência e a troca de experiências de vida, ou seja, a socialização sempre se mostrou como algo indispensável ao ser humano, pois um ser não evolui mediante a falta de comunicação. Sendo assim, a linguagem é, antes de tudo, social. Portanto, sua função inicial é a comunicação, expressão e compreensão. É por meio das relações sociais que o ser humano aprende e ensina, constrói e desconstrói conhecimento. "A constante interação entre o sujeito e o mundo exterior é o processo pelo qual se dá o desenvolvimento intelectual humano" (Piaget, 1978). Assim sendo, a concepção de linguagem mais aceita atualmente é a que compreende a língua como uma atividade coletiva, realizadora de ações através da interação social e cognitiva.

Para o desenvolvimento do homem, sempre se mostrou necessário o espaço comunicativo, o espaço onde possa ter interações dentre as diversas culturas construídas. A interação de um indivíduo com o grupo social ao qual pertence ou em que se encontra inserido ocorre quando este passa a assimilar a cultura desse grupo social. Essa interação só é possível por meio da comunicação, do diálogo, da expressão, da troca de ideias, ou seja, por intermédio da linguagem. "É preciso pensar a linguagem humana como lugar de interação, de constituição das identidades, de representação de papéis, de negociação de sentidos, por palavras, é preciso encarar a linguagem não apenas como representação do mundo e do pensamento ou como instrumento de comunicação, mas sim, acima de tudo, como forma de interação social” (Koch, 2003).

Com o passar dos anos, o homem foi evoluindo e inovando. Com efeito, diante do avanço da globalização, criaram-se os primeiros meios de comunicação e interação social digital, sendo alguns deles: o telégrafo, que permite a comunicação por meio de códigos; o correio, que permite o envio de cartas, documentos e encomendas; os jornais, que anunciam notícias impressas; o radio que através de sinal eletromagnético possibilita a comunicação em massa com o efeito sonoro; os telefones, que por sinal eletroacústico possibilita a interação sonora (voz); e as televisões, que são capazes de reproduzir imagens e áudios de forma instantânea, convertendo ondas eletromagnéticas em luz e som.

Após essa era e com o avanço tecnológico significativo, a Tecnologia da Informação e Comunicação (TIC) pode ser definida como um conjunto de recursos tecnológicos, utilizados de forma integrada, com um objetivo comum. As TIC's são utilizadas das mais diversas formas: na indústria (no processo de automação), no comércio (no gerenciamento e nas diversas formas de publicidade), no setor de investimentos (informação simultânea, comunicação imediata) e na educação (no processo de ensino aprendizagem, na Educação a Distância). O desenvolvimento de hardwares, como os novos telefones (os chamados "smartphones") e os computadores, tanto os antigos de tubo, quanto os novos e potentes desktops, além de notebooks e softwares, garante a operacionalização da comunicação e dos processos decorrentes em meios virtuais. No entanto, foi a popularização da internet que potencializou o uso das TIC's em diversos campos.

A internet abriu um leque de formas comunicativas em escala global, possibilitando uma interação social entre todas as culturas mundiais. Hoje, comumente, uma pessoa que mora no Brasil, por exemplo, pode interagir, por meio da internet, com alguém do outro lado do globo terrestre, se estiverem conectados. Mas nem sempre foi assim. Antes, a internet era um privilégio de poucos. A rede mundial de computadores chegou ao mundo na década de 70, mas só a partir dos anos 2000 ela se tornou de fácil acesso e utilizável pela grande população. Tendo em vista o grande uso da internet em escala global, ela se tornou necessária para o cotidiano de muitos, otimizando a vida em diversos aspectos. 


\section{As Tecnologias Digitais}

\subsection{Realidade Aumentada}

O termo "Realidade Aumentada" (RA) foi criado em 1992 pelo cientista e pesquisador Thomas P. Caudell durante o desenvolvimento de uma das aeronaves mais famosas do mundo: o Boeing 747. Caudell, no intuito de otimizar o processo de montagem das aeronaves, devido ao tempo excessivo que os operários gastavam para interpretar as complexas instruções de montagem, resolveu criar um sistema que os auxiliassem a agilizar esse processo, porém não obteve sucesso. Nesse contexto, surgiu o conceito de Realidade Aumentada. Atualmente, a RA está presente em diversos setores da sociedade, como em hospitais, fabricação de veículos, esportes e também em empresas aeroespaciais.

\subsection{Reconhecimento Facial}

A presença do reconhecimento facial parece ser recente, porém ela foi primeiramente apresentada no século passado. Os estudos acerca do reconhecimento facial tiveram início no ano de 1960, pelos cientistas Woody Bledsoe, Helen Chan Wolf e Charles Bisson. Porém, devido às limitações tecnológicas da época, eles não obtiveram sucesso. Então, em 1970, seus sucessores utilizaram novos parâmetros para o funcionamento do programa de reconhecimento facial e, finalmente, no ano de 1990, foi criado, pelos cientistas Sirovich e Kirby, o primeiro sistema de reconhecimento facial, que foi batizado de Eigenface. Atualmente, o reconhecimento está presente em diversos lugares, e se tornou uma ferramenta de uso popular, estando presente em smartphones, notebooks e até mesmo em veículos mais avançados.

\subsection{Inteligência Artificial}

O desenvolvimento das inteligências artificiais teve início logo após o término da segunda guerra mundial, com o artigo "Computing Machinery and Intelligence", do matemático inglês Alan Turing, mas o nome "Inteligência Artificial” só foi criado em 1956. Seus principais idealizadores foram os cientistas Herbert Simon, Allen Newell, John McCarthy, Warren McCulloch, Walter Pitts e Marvin Minsky, entre outros. O ser humano sempre buscou formas de automatizar processos, como a fabricação de produtos dos mais variados tipos. Porém, essa automatização por meio de máquinas apenas obedecia a comandos apresentados anteriormente e que não possuíam a capacidade de aprendizado. Então, com a criação das IAs, isso mudou. Além de obedecerem a comandos propostos anteriormente, elas possuíam a capacidade de aprendizado, mesmo que em uma proporção inferior à do ser humano. Esses sistemas têm, como características básicas, a capacidade de raciocinar, aprender e reconhecer padrões. As IA's mais famosas presentes em nossa sociedade são a Siri (Apple), Cortana (Microsoft) e Alexa (Amazon).

\section{5. Ética na Evolução da IHM}

Desde a primeira Revolução Industrial no século XVIII, a sociedade embarcou numa condição de progredir na medida em que se descobre novas formas de produzir ou realizar umproduto de valor comercial, bélico ou de grande impacto na melhoria e aprimoramento das configurações desse corpo social. Logo, em um ponto específico e importante desse processo, se vê, como consequência, a evolução exponencial da comunicação e informatização. Enquanto estrutura social, "a sociedade informatizada tem sido possível graças a um conjunto de tecnologias de comunicação e de informação" (Floridi, 2002). Por si só, essa revolução digital acometeu na interpretação do espaço em que vive a sociedade, em suas atividades políticas, econômicas e sociais.

Desse modo, é de se esperar um impacto em normas e valores éticos que impõem o certo e o errado em meio a novas possibilidades e condições da entidade humana em nível global. Em resumo, pode-se dizer que "a sociedade informacional atual cada vez mais depende da tecnologia para prosperar, mas, por outro lado, também precisa de um ambiente saudável e 
natural para florescer" (Floridi, 2009). Portanto, o cenário de intensificação da interação entre o ser humano biológico e a máquina artificial é um campo, também, do surgimento de crises éticas e dilemas morais.

Nesse contexto, cita-se, como primeira problemática desse ambiente ético, a criação e o desenvolvimento de uma Inteligência Artificial (IA). A IA se resume em criar um tipo de inteligência comparável à de um ser humano, por meio de uma estrutura artificial, escrita em linguagens de entendimento computacional e eletrônico. Além disso, a essência da construção dessa tecnologia se define em simular a entidade humana na sua capacidade cognitiva, colocando em evidência a intenção do Homo Sapiens em recriar-se. A partir dessa ideia, o corpo ético social oscila e revela partes em que a IA não se define como benéfico ou perigoso para a sociedade. Enfatizando o problema, “o erro da ética até o momento tem sido a crença de que só se deve aplicá-la em relação aos homens" (Schweitzer, 1950). Logo, surgem instâncias das formas de se lidar com a IA, sendo uma dessas formas relacionadas com o campo da biologia, mais especificamente à definição da IA como uma nova espécie.

Voltando à história, pode-se destacar os chamados "Neandertais". Em definição, os Homens de Neandertal, ou Homo neanderthalensis, foram uma espécie do mesmo gênero do atual homem moderno, desaparecida há cerca de 40.000 anos, e “eram tão inteligentes, habilidosos, solidários e criativos quanto nós, os homo sapiens" (Altares, 2021). Os Homo neanderthalensis, portanto, foram uma espécie semelhante ao ser humano atual, e algumas diferenças em sua estrutura corporal e formação do cérebro não foram capazes de impedir uma interação e comunicação com os Sapiens. Entretanto, de que forma isso se relaciona com a problemática da IA? Justamente pela grande semelhança da situação de ambos. Atualmente, as IA's possuem um potencial poder de inteligência comparável a dos animais supracitados e, paralelamente, podem se apresentar em corpo físico, além de poder apresentar consciência definida. Com isso, elas são como uma nova espécie coexistindo com os homens modernos, como o robô Sophia por exemplo.

Conforme apontado por Parsons (2016), Sophia é um robô humanoide desenvolvido pela empresa Hanson Robotics, de Hong Kong, capaz de reproduzir 62 expressões faciais. Produzida em 2015, Sophia é uma inteligência artificial em um corpo eletrônico hábil a imitar características humanas, através de falas e expressões de felicidade, raiva e tristeza. Este robô representa, então, um primoroso projeto de IA. Além disso, segundo Pancini (2021), a empresa chinesa Hanson Robotics, responsável pelo robô dirigido por inteligência artificial, anunciou que planeja produzir em massa quatro modelos, incluindo Sophia, até o final de 2021. Portanto, além da criação de um "ser humano" artificial capaz de se comunicar sozinho, a empresa irá produzir mais espécimes do mesmo tipo. Compilando as informações, pode-se concluir que Sophia é uma simulação da inteligência e do corpo humano, capaz de interagir com o homem moderno através de falas e expressões faciais, sendo parte fundamental do processo de comunicação, abrindo a possibilidade de afeto e relação ou até empatia e identificação. O interesse do Homo Sapiens contemporâneo em buscar incansavelmente uma evolução de suas ferramentas tecnológicas para uma interação e comunicação cada vez mais intensa é evidenciado.

De fato, Sophia pode ser comparável a uma espécie paralela ao Sapiens, assim como foram os Neandertais, e como toda espécie busca se reproduzir para conquistar o meio em sua volta. Segundo Harari (2018), a inteligência artificial vai tornar os profissionais irrelevantes e hackear seres humanos. Pode-se, então, evidenciar neste determinado ponto uma crise ética com diversas perguntas: o robô Sophia ou qualquer outra IA do tipo é uma vida? E se sim, tem direitos iguais aos dos Homo Sapiens? Se os Homo Sapiens foram os responsáveis pela extinção dos Neandertais, os robôs Sophia não poderiam fazer o mesmo com eles? Seria então um perigo para a sociedade, ou apenas se trata de um "upgrade" nas tecnologias digitais desse mercado que cresce exponencialmente? Um dilema moral é requisitado para responder tais perguntas. Enfim, é clara a percepção e quebra desses valores acerca da vida e da convivência entre seres humanos e máquinas, gerando a necessidade de se discutir esses dilemas a favor de determinar o certo e o errado no caminho de evolução constante da Interação HomemMáquina. 


\section{Interdependência entre Homens e Máquinas}

Analisando criticamente a época da Primeira Revolução Industrial, pode-se afirmar que "possibilitou à humanidade a descoberta de novos meios para se converter energia e produzir bens, transformando a sua dependência pela natureza e os ritmos da agricultura tradicional em cronograma preciso e uniforme da indústria” (Harari, 2018). Essa inversão produziu forte influência na forma como as máquinas funcionam, no cotidiano e na mentalidade de trabalho das pessoas, pois uma depende da outra para "sobreviver". Em exemplo, considerando-se um computador ou qualquer motor mecânico, cada um possui um tempo sincronizado para a realização de seus processos.

Um motor mecânico, para poder realizar um movimento da roda de um carro, ou o movimento das palhetas de um avião, necessita de um processo quantificado e organizado em realizar a combustão e favorecer a lógica de movimento. Do mesmo modo, o computador, para fazer aparecer no monitor a letra da tecla pressionada no teclado, necessita de identificação, criptografia e um tempo sincronizado e organizado das ações. $\mathrm{O}$ dono desses equipamentos são os humanos que, para poder manipulá-los, precisa se conformar com a lógica de funcionamento dessas tecnologias. Portanto, isso pode ser visto em forte presença nas pequenas e grandes atividades da sociedade, como os horários e pontos específicos das paradas de ônibus, a presença de relógios e mapas em aparelhos celulares e computadores, e toda outra forma de cronometragem feita para se adequar à realidade, com a finalidade de haver uma noção por parte de cada um com relação à produção e posicionamento. Sabendo lidar com as máquinas e convivendo com elas, os humanos passam a se comportar equiparativamente.

Nessa perspectiva, não há uma relação homem vs máquina, mas sim homem com máquina (Universal Robots Brasil, 2020). Além disso, essa convivência também originou um processo de dependência. A sociedade humana já chega a aproximadamente 8 bilhões de pessoas e, sem as máquinas que ajudam na produção de alimentos, esse número seria insustentável. Computadores atuando como servidores guardam informações sobre moedas digitais, e até mesmo o perfil de cada cidadão, com as informações de seu RG e CPF. Em exemplo, se um dia os servidores de um determinado centro de pesquisa pegasse fogo, danificando todos os discos rígidos desses servidores, diversos artigos digitalizados seriam completamente perdidos. Portanto, no atual século XXI, a sociedade de Homo Sapiens se vê cercada e extremamente dependente de tecnologias digitais.

\section{Análise dos Dados Coletados}

A pesquisa teve como objetivo analisar o comportamento do público em interação com máquinas e serviços digitais. No total, 39 informantes atenderam ao questionário. 
Figura 1: Relação de idade do público pesquisado.

\section{Quantos anos você têm?}

39 respostas

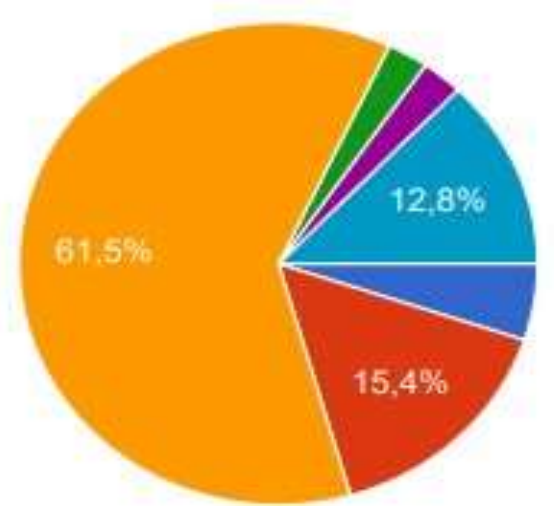

Abaixo de 14 anos

Entre 13 e 18 anos

Entre 17 e 21 anos

Entre 20 e 25 anos

Entre 24 e 31 anos

Acima de 30 anos

Fonte: Dados dos autores.

Na Figura 1, referente à idade do público pesquisado, percebe-se que a grande maioria dos que se dispuseram a responder são jovens, significando uma maior adesão do público nascido em anos em que a internet e equipamentos derivados começaram a surgir popularmente ao redor do mundo.

Figura 2: Relação do grau de dependência por tecnologias digitais
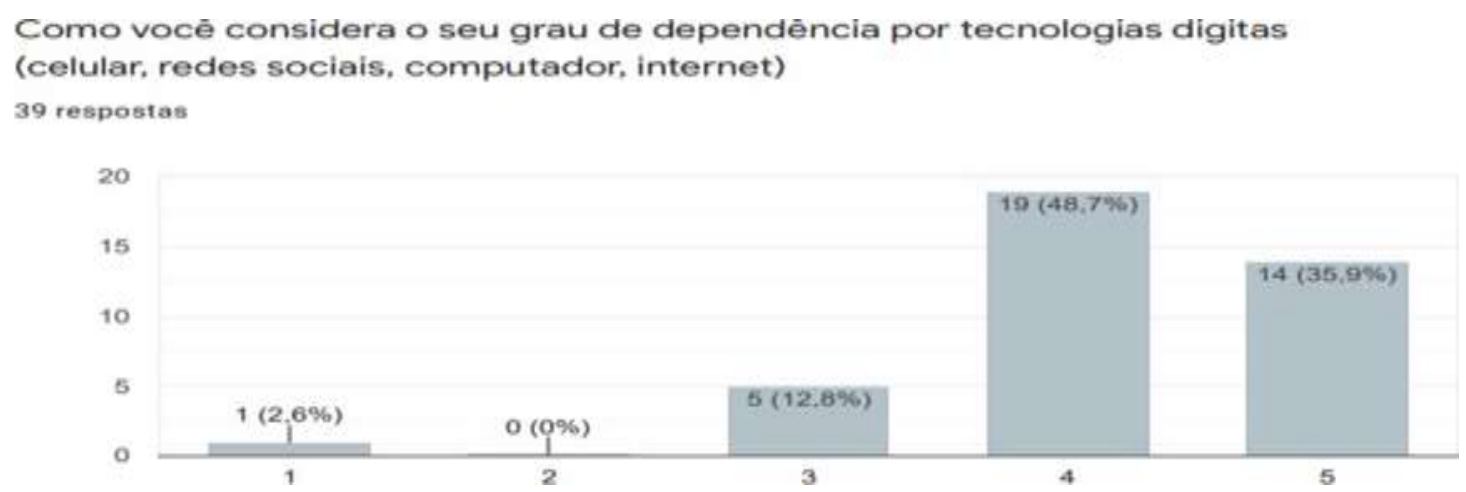

Fonte: Dados dos autores.

No que diz respeito à Figura 2, correspondente à relação do grau de dependência das pessoas por tecnologias digitais, identifica-se que a maioria se considera dependente das tecnologias digitais, sendo elas de grau 4 ou 5 de dependência, somando 84,5\% dos pesquisados. Em análise, é possível reafirmar o alto nível de interdependência entre os seres humanos modernos (principalmente os mais jovens) e as máquinas. 
Figura 3: Relação do principal meio de comunicação utilizado.

\section{Qual o seu principal meio de comunicação hoje?}

39 respostas

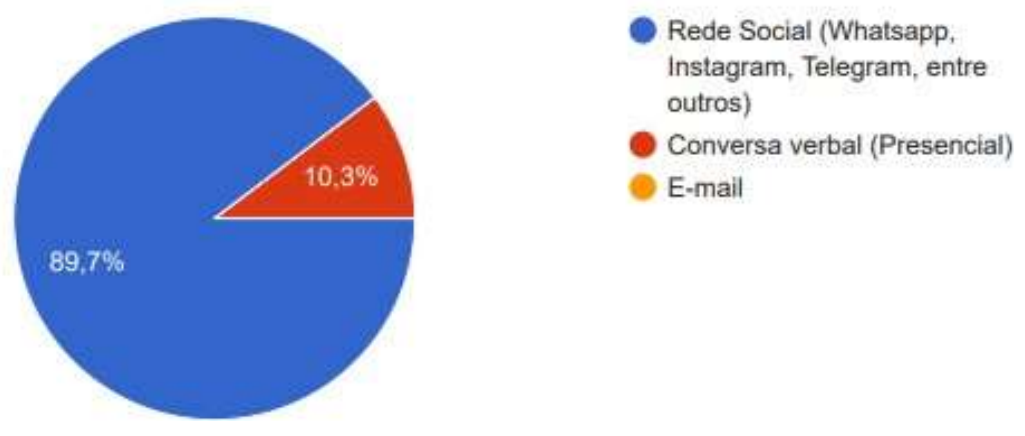

Fonte: Dados dos autores

Com relação à Figura 3, relacionada ao questionamento do principal meio de comunicação utilizado pelas pessoas, pode-se observar que grande parte dos informantes utiliza a tecnologia para se comunicar, comparativamente à conversa face a face. Nota-se uma mudança de paradigma em que a sociedade representa na comunicação a sua forma de interação com o mundo. Nesse aspecto, nota-se que os recursos tecnológicos não trouxeram apenas comodidade e novas possibilidades de ferramentas que facilitarem o acesso a informação e a facilidade de comunicação, mas também uma nova forma de comunicação, quase difundida entre humano e máquina, de tal maneira que a alta dependência desses recursos permitiram que o homem tivesse um comportamento frente à comunicação diferente a tempos anteriores.

Nesta relação, é possível perceber algo discutido anteriormente no presente artigo, quando se questionou se Inteligências Artificiais poderiam ser consideradas como novos "seres vivos" e deveriam ter direitos assim como os humanos. Analisando o gráfico, percebe-se que a menor parte das pessoas que responderam acredita que uma IA possa estabelecer uma relação de amizade com um ser humano, fato que se deve por conta de uma amizade envolver questões sentimentais e pela forma como são tratados culturalmente ao longo do tempo, seja em filmes, livros, entre outros, em que robôs são tidos como seres capazes de pensar, mas que são assentimentais, algo que talvez seja apenas uma ideia errônea de que ainda pode e será muito discutido em paralelo ao avanço das tecnologias digitais e inteligentes. 
Figura 4: Relação de quantas pessoas acham correta a sociedade ser automatizada.

\section{Você acha correto que a nossa sociedade possa ser automatizada por máquinas e algoritmos? Pense em carros com direção automática, uma IA realizando o trabalho de um advogado, aviões sem tripulação, cirurgias sem um cirurgião humano.}

39 respostas

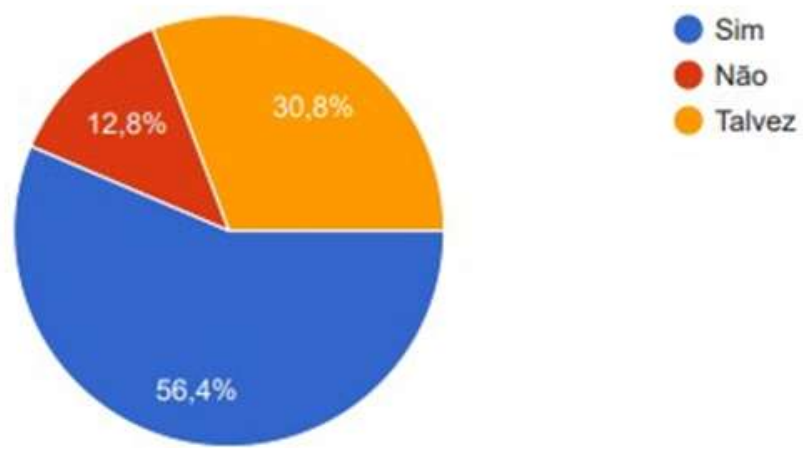

Fonte: Dados dos autores.

No que diz respeito à Figura 4, correspondente à aceitação ou não das pessoas frente ao fenômeno da automatização da sociedade, percebe-se que mais da metade dos entrevistados acredita que, sim, é correto que a sociedade seja automatizada através de máquinas e algoritmos, mas que uma parcela muito grande, superior a 30\%, ainda apresenta dúvida quanto a isso, talvez por desinformaçãoe conceitos pré-estabelecidos, como citado no item anterior.

Figura 5: Relação de interesse quanto à inovação tecnológica.

\section{Qual o seu nivel de interesse em inovações tecnológicas?(Um celular com uma nova funcionalidade, uma ferramenta de trabalho)}

39 respostas

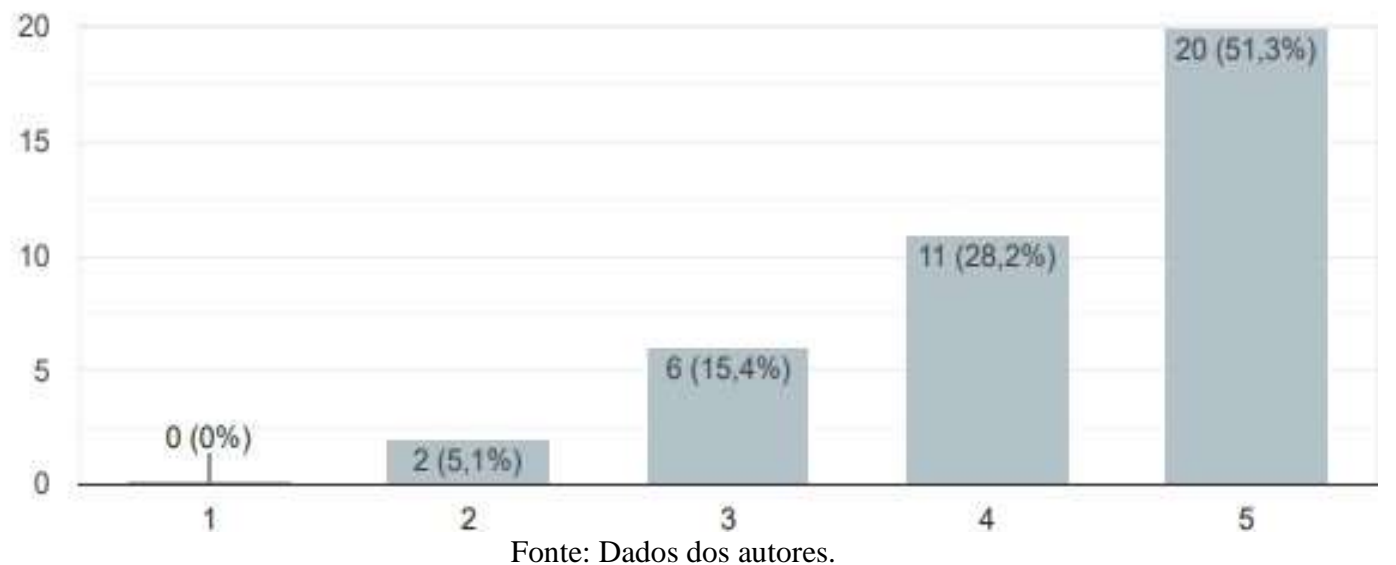

No que diz respeito à Figura 5, relacionada ao interesse das pessoas quanto à inovação tecnológica, nota-se que a grande parte do público apresenta um interesse elevado em inovações tecnológicas, com todos os questionados apresentando pelo menos um interesse em nível $2 / 5$, tendo sua concentração maior no nível máximo de interesse, fato esse que demonstra a 
gigante gama de possibilidades que a tecnologia digital proporcionou e proporciona, criando expectativa com relação aos avanços que ainda podem ocorrer.

Figura 6: Relação do nível de desconforto em passar 24h longe de tecnologias digitais.
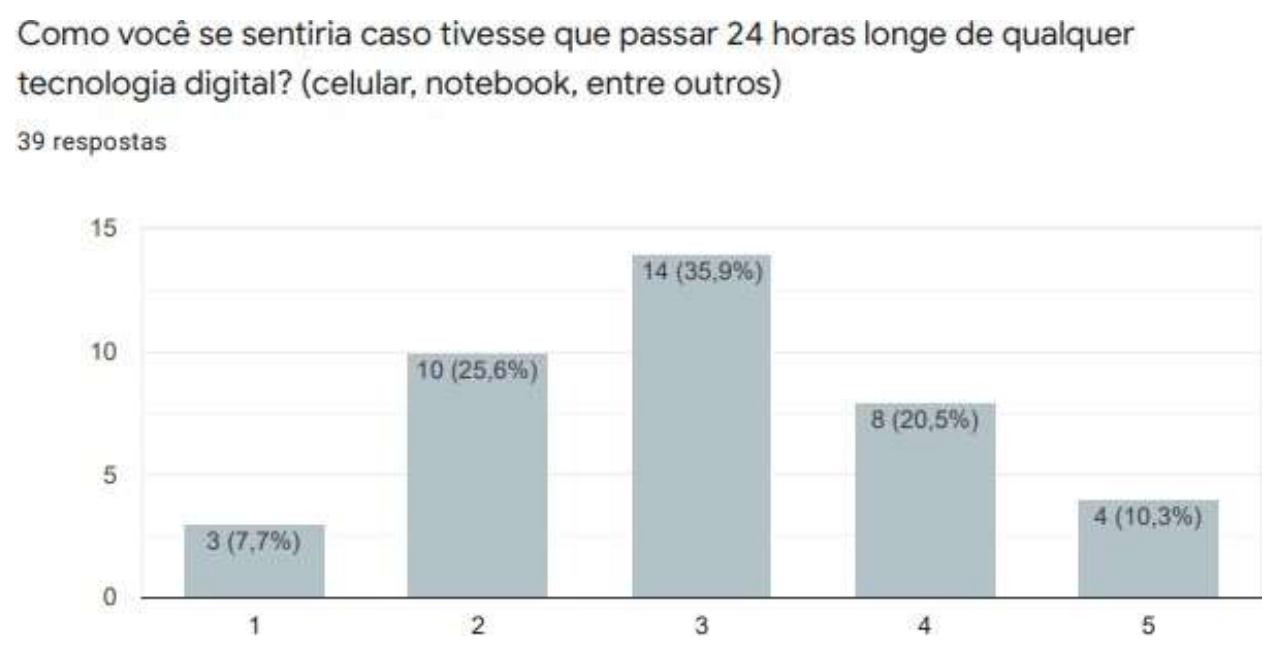

Fonte: Dados dos autores.

Com relação à Figura 6, referente ao nível de desconforto das pessoas quando passam 24 horas longe de qualquer tecnologia digital, fica claro que a interação homem-máquina tomou conta do mundo e cada vez mais seres humanos tornam-se dependentes das máquinas. Como mostrado no gráfico, a grande maioria apresentou um desconforto de, no mínimo, grau 3/5 em passar apenas um dia longe de qualquer tecnologia digital, onde fica visível a dependência tecnológica dos seres humanos no século XXI. Assim sendo, é claramente perceptível a tamanha importância que as máquinas conquistaram ao longo dos anos, a ponto de tornarem-se indispensáveis para a comunicação humana moderna, tomando conta das mais diversas áreas.

\section{Considerações Finais}

De fato, é enraizada a Interação Homem-Máquina na sociedade atual de Homo Sapiens, causando dependência e intensa comunicação. Além disso, é provado que essas relações acontecem com frequência diante da pesquisa realizada de acordo com a metodologiado presente artigo. Na comunicação, os veículos digitais fizeram uma revolução, onde as pessoas geralmente utilizam mais os meios tecnológicos digitais como forma de comunicação do queos meios naturais, como por exemplo: as conversas diretas e presenciais. Apesar disso, a discussão sobre a ética dessas ações e dilemas morais devem ser debatidas, pois ainda não há respostas concretas que determinem quais pontos dessa revolução tecnológica apresentam um malefício, uma ameaça ou um futuro próspero e de paz. Enfim, essa interdependência entre os Homo Sapiens e as máquinas é duradoura e dificilmente será quebrada, por ser extremamente conveniente e o principal "workflow" do atual século XXI.

$\mathrm{O}$ presente artigo pode, ainda, sugerir uma metodologia mais abrangente que aborde o seu tema, trazendo maiores variáveis à essa linha de pesquisa, baseando-se fortemente nas ideias principais do envolvimento do homem com a tecnologia, criando a possibilidade de maiores discussões e debates éticos acerca do assunto. 


\section{Referências}

Altares, G. (2021). E se nós formos os neandertais? As últimas descobertas genéticas reabrem o debate sobre a possibilidade de que esta espécie não tenha se extinguido, mas foi integrada aos 'sapiens'. El País. https://brasil.elpais.com/ciencia/2021-04-10/e-se-nos-formos-os-neandertais.html.

Big House Web. (2019). Como surgiu a inteligência artificial? Big House Web. https://blog.bighouseweb.com.br/como-surgiu-a-inteligencia-artificial/.

Boccard, T. (2020). Usos e riscos do reconhecimento facial. Use Mobile. https://usemobile.com.br/usos-reconhecimento-facial/.

Carnevalli, E. (2019). “A inteligência artificial vai tornar os profissionais irrelevantes e 'hackear' seres humanos”. Época Negócios. https://epocanegocios.globo.com/Tecnologia/noticia/2019/11/inteligencia-artificial-vai-tornar-os-profissionais-irrelevantes-e-hackear-seres-humanos.html.

Cervo, A. L.; Bervian P. A. (2002). Metodologia Científica. Prentice Hall.

Floridi, L. (2002). Information Ethics: As Environmental Approach to the Digital Divide. Philosophy in the Contemporary World, 9 (1), 39-45. https://doi.org/10.5840/pcw2002915.

Floridi, L. (2009). The Information Society and Its Philosophy: Introduction to the Special Issue on "The Philosophy of Information, Its Nature and Future Developments". The Information Society: An International Journal, 25 (3), 153-158. https://doi.org/10.1080/01972240902848583.

Gil, A. C. (1999). Métodos e técnicas de pesquisa social. Atlas.

Harari, Y. N. (2018). Sapiens: uma breve história da humanidade. L\&PM Editores S. A.

Hautsch, O. (2009). Como funciona a Realidade Aumentada. TecMundo. https://www.tecmundo.com.br/realidade-aumentada/2124-como-funciona-arealidade-aumentada.htm.

Koch, I. V. (2003). A interação pela linguagem. Contexto.

Magalhaes, P. L. (2010). Influências da evolução tecnológica na comunicação humana: estudo das redes sociais. Belo Horizonte: Universidade FUMEC. https://www.academia.edu/https://www.academia.edu/37741204/Influ\%C3\%AAncias_da_evolu\%C3\%A7\%C3\%A3o_tecnol\%C3\%B3gica_na_comunica\%C3 $\%$ A7\%C3\%A3o_humana_estudo_das_redes_sociais\#: :text=PATRICK\%20LEANDRO $\% 20$ MAGALH\%C3\%83ES\%20Influ\%C3\%AAncias\%20da,humana $\% 3 \mathrm{~A} \% 20$ estudo $\% 20$ das $\% 20$ redes $\% 20$ sociais.\&text $=0 \% 20$ presente $\% 20$ estudo $\% 20$ visa $\% 20$ responder,sendo $\% 20$ enfatizadas $\% 20$ as $\% 20$ redes $\% 20$ sociais.

Oliveira, F. F. R. de; Ferreira, M. M.; \& Furst, A. (2013). Estudo da usabilidade nas interfaces homem-máquina. E-xacta, 6 (2), 93-105. http://dx.doi.org/10.18674/exacta.v6i2.1079.

ONU NEWS. (2019). Estudo da ONU revela que mundo tem abismo digital de gênero. ONU News. https://news.un.org/pt/story/2019/11/1693711.

Pacievitch, T. (2021). Tecnologia da Informação e Comunicação. Info Escola. https://www.infoescola.com/informatica/tecnologia-da-informacao-ecomunicacao/.

Pancini, L. (2021). Robô Sophia, que imita expressões faciais, começa a ser produzida em massa: Empresa criadora do robô acredita que ele pode ser essencial para alguns serviços durante a pandemia. Exame. https://exame.com/tecnologia/robo-sophia-que-imita-expressoes-faciais-comeca-a-ser-produzida-emmassa/.

Parsons, J. (2016, 22 mar). Watch Sophia the 'sexy robot' claim she will 'destroy humans' - leaving creator red faced: A mistake during a technical demonstration at the SXSW tech show revealed the android's true intentions. Mirror. https://www.mirror.co.uk/tech/watch-sophia-sexy-robot-claim-7606152.

Piaget, J. (1978). A formação do símbolo na criança. Zahar.

Rosa, J. G. S., \& Moraes, A. M. (2010). Avaliação e projeto no design de interfaces. 2AB Editora.

Schweitzer, A. (1950). Aus meinem Leben und Denken. Hamburg: R. Meiner Verlag.

Sousa, R. (2019). Meios de comunicação. UOL - Mundo Educação. https://mundoeducacao.uol.com.br/geografia/meios-comunicacao.htm.

Suzanna. (2018). A influência das redes sociais na comunicação humana. Cesar. https://www.cesar.org.br/index.php/2018/08/27/a-influencia-das-redessociais-na-comunicacao-humana/.

Universal Robots Brasil. (2020). Repensando a relação homem x máquina. Universal Robots Brasil. https://www.universal-robots.com/br/blog/repensando-arelac\%C3\%A3o-homem-X-m\%C3\%A1quina/. 